\title{
Efficacy and safety of percutaneous computed tomography-guided microwave ablation for colorectal cancer, oligometastatic liver-only disease: a single center's experience
}

\author{
Maria Tsitskaria, Dimitris Filippiadis ${ }^{b}$, Periklis Zavridis ${ }^{a}$, Argyro Maziotib ${ }^{b}$ Thomas Vrachliotis ${ }^{d}$, \\ Leonidas Alevizos', Elias Brountzos ${ }^{b}$, Nikos Kelekis ${ }^{b}$
}

American Medical Center, Nicosia, Cyprus; Attiko University General Hospital, Athens, Greece; Ammochostos

General Hospital, Cyprus; Henry Ntynan Hospital Center, Greece

\section{Abstract}

\section{Introduction}

Colon cancer is a common clinical entity throughout the world. It is the most common cancer in Europe and the

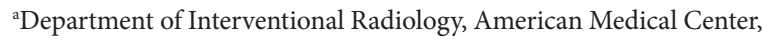
Nicosia, Cyprus (Maria Tsitskari, Periklis Zavridis); ${ }^{b}$ Department of Interventional Radiology, Attiko University General Hospital, Athens, Greece (Dimitris Filippiadis, Argyro Mazioti, Elias Brountzos, Nikos Kelekis); 'Department of General Surgery, Ammochostos General Hospital, Cyprus (Leonidas Alevizos); ${ }^{d}$ Department of Interventional Radiology, Henry Ntynan Hospital Center, Greece (Thomas Vrachliotis)

Conflict of Interest: None

Correspondence to: Maria Tsitskari, MD, PhD, EBIR, Epidavrou 7A, Strovolos, Nicosia, Cyprus, e-mail: mariadote@hotmail.com

Received 7 February 2020; accepted 26 June 2020;

published online 5 October 2020

DOI: https://doi.org/10.20524/aog.2020.0545 third most common worldwide [1,2]. For metastatic liver disease secondary to colorectal cancer, apart from systemic chemotherapy, additional therapeutic options include surgery and interventional oncology techniques, such as percutaneous thermal destruction of metastatic lesions, or loco-regional control of metastatic liver disease with intra-arterial therapies. Both local thermal ablation and loco-regional intra-arterial therapies have been incorporated into the toolkit of the recently published guidelines of the European Society for Medical Oncology for the treatment of metastatic colon cancer, as potential treatment options for patients with oligometastatic disease [3]. Patients with oligometastatic disease may undergo thermal ablation as monotherapy or in combination with surgical resection, either initially or after initiation of systemic chemotherapy; the goal is to achieve long-term disease control and potentially radical treatment without the need for ongoing systemic therapy [3].

Percutaneous microwave ablation (MWA) is a relatively new method of thermal catalysis growing in popularity because 
of its potential advantages over radiofrequency ablation (RFA), which include, but are not limited to larger ablation zones in a shorter time frame, higher temperature profiles, and being less affected by the "heat-sink effect" and by tissue impedance [4].

The purpose of this study was to evaluate the efficacy and safety of percutaneous MWA in oligometastatic patients with colorectal cancer liver-only disease in clinical practice. In addition, the survival and the potential factors affecting the survival of these patients were analyzed.

\section{Patients and methods}

The study protocol conformed to the ethical guidelines of the 1975 Declaration of Helsinki, as reflected by a priori approval by the institution's human research committee.

\section{Patients}

Institutional database research identified 32 patients with metachronous hepatic metastases from colorectal cancer, treated with MWA between August 2012 and September 2018, who either were not surgical candidates $(n=28)$ or refused surgery $(n=4)$. All patients were referred for MWA by the oncology multidisciplinary team of our institution. The study's inclusion criteria were oligometastatic colorectal cancer with liver-only metastatic disease $(<5)$ and a maximum lesion diameter of $4 \mathrm{~cm}$ per lesion. Exclusion criteria were: the presence of extrahepatic metastases; coagulation disorders; clinical signs of liver failure, such as excessive ascites or encephalopathy; acute or advanced renal disease; and signs of acute infection. The diagnosis of metastatic liver disease was made using computed tomography (CT) or magnetic resonance imaging (MRI) scanning.

\section{Procedure}

All patients were informed in detail about the whole procedure, the potential risks and complications; all gave signed written consent. All MWA procedures were performed by 2 experienced interventional radiologists under CT guidance, using 2 different commercially available systems, AMICA (HS, Italy) and Emprint (Medronic, UK). Conscious sedation was administered to all patients during the procedure by an anesthesiologist.

MWA was always performed in an inpatient setting. CT guidance with sequential scanning $(120 \mathrm{Kv}$ peak, $240 \mathrm{mAs}$ wavelength and $2 \mathrm{~mm}$ slice thickness) was used for planning, targeting and intraprocedural modification during the ablation session. A combination of local anesthesia (performed by the interventional radiologist) and conscious sedation with fentanyl (delivered by the anesthesiologist) was used to treat intraprocedural pain. Under extended local sterility, MWA was performed via a percutaneous approach in all cases. After the initial CT scan, a skin entry point was selected. A microwave antenna was inserted to the lesion of interest and its approach was evaluated with sequential CT scans. Once the antenna was in the correct location, the ablation session was performed according to the guidelines provided by the manufacturer concerning quantity of energy (W), duration (min) and resultant ablation volume $(\mathrm{cm})$. Whenever deemed necessary, the microwave antenna was repositioned and another ablation session was performed. The goal was to ablate the whole lesion, including a circumferential zone of surrounding normal liver parenchyma with minimum width $0.5 \mathrm{~cm}$. CT was used to assess the ablation zone and potential immediate complications at the end of the ablation treatment. At the end of the procedure all patients were hospitalized for 1 day for hemodynamic monitoring and analgesia administration to control postprocedural pain.

\section{Follow up}

All patients were followed-up with liver CT or MRI scan. The same imaging method as in the preprocedural screening was selected. The follow-up protocol included imaging at 1, 3, 6 and 12 months after ablation and every 6 months thereafter. The presence of ovoid-like, non-enhancing lesions was considered to represent areas of necrosis. Primary local tumor control was defined as a lack of enhancement of the target tumor immediately after the procedure. Secondary local tumor control was defined as the absence of contrast enhancement after a repeated session. Complete necrosis was defined as the absence of contrast enhancement 3 months after the ablation. During the follow up, the ablated tumors were categorized into 2 groups according to the imaging findings: tumors with local tumor control (lack of enhancement of the ablation zone), and tumors with local tumor progression (appearance of new focal areas of enhancement within or in proximity to the ablation zone). The presence of new metastases was also recorded. In the event of local tumor progression or the presence of new metastases, patients were evaluated for a new MWA procedure, depending on the technical feasibility, the likelihood of achieving local tumor control, and the patient's overall condition.

\section{Clinical endpoints and statistical analysis}

The clinical endpoints of our study were the 5-year overall survival and 5-year disease-free survival for each patient, as well as the time to tumor progression (TTP) for each individual lesion. The TTP for each individual lesion was calculated from the date of MWA. The time to the appearance of new metastases was calculated from the date of MWA until the appearance of new metastases in any anatomical position other than the original ablation site. Overall survival was defined as the time from the first MWA until the time of death from the disease, or until the time of last contact with the patient. Patients who died of other causes were excluded from the statistical analysis.

Quantitative data were expressed as mean, median or range. Overall survival and disease-free survival analyses were performed using the Kaplan-Meier method with the $\log$ rank test. Cox proportional hazards analysis, which 
estimates the odds ratio within 95\% confidence intervals, was used to determine independent prognostic factors. Local tumor progression, new liver metastases and extrahepatic disease in the various subgroups of patients, determined by their clinicopathological variables, were compared using the chi-square test (Pearson, Mantel-Haenzel test for linear association), with Yates' correction or Fisher's exact test whenever needed. For all statistical tests, $\mathrm{P}$-values of $<0.05$ were considered significant. The statistical analysis was performed using SPSS 18.0 (SPSS Inc, Chicago, Ill).

The definition of complications was assigned according to the Cardiovascular and Interventional Radiological Society of Europe (CIRSE) classification system [5].

\section{Results}

In total, 32 patients ( 21 men, 11 women) with colorectal liver metastases, mean age $72( \pm 9.94)$ years, were included in our study. The primary tumor for the majority of patients was in the colon $(n=27)$, while in 5 patients it was located in the rectum. Sixteen patients had 1 liver metastasis, 11 patients had 2, 4 patients had 3, and 1 patient had four metastasis Lesions from $0.8 \mathrm{~cm}$ up to $3.9 \mathrm{~cm}$, with median diameter of $2 \mathrm{~cm}$, were treated. Patients' demographics and clinicopathological characteristics are given in Table 1 .

A total of 58 lesions were treated in 45 ablation sessions. In Fig. 1 we can see the example of a patient with a history of colorectal cancer and metachronous solitary hepatic lesion treated with MWA. Four of these lesions were new metastases that appeared during the follow-up period. Primary local tumor control was achieved in $91.3 \%$ (53/58) of the ablated lesions. In 5 patients MWA was considered incomplete and it was repeated within $24 \mathrm{~h}$. Secondary local tumor control was achieved in $100 \%$ of the treated lesions. Complete necrosis was obtained in $49 / 58(84.4 \%)$ of the ablated lesions. In relation to the size of the lesions, complete necrosis was seen in 35/38 (92\%) metastases with diameter $<2 \mathrm{~cm}, 12 / 16$ (75\%) metastases with diameter 2.1-3 cm and 2/4 (50\%) metastases with diameter $3.1-4 \mathrm{~cm}$.

Patients were followed-up over a period of 5 years. During the follow-up period, local tumor progression, as first sign of disease recurrence, was recorded in 8 patients (25\%). In Fig. 2 we can see an example of one patient with rectal cancer and metachronous hepatic metastases, who had a recurrence 12 months after initial treatment with MWA. New hepatic metastases, as first sign of recurrence, were recorded in 19 patients (59.4\%), while $40.6 \%$ of these patients also developed extrahepatic disease. Patients with at least one lesion greater than $2 \mathrm{~cm}$ in diameter developed new hepatic metastasis more often compared to those with lesions smaller than $2 \mathrm{~cm}$ at initial presentation $(68.42 \%$ vs. $31.58 \%$, $\mathrm{P}=0.04$ ). Moreover, the total number of liver metastases at presentation predicted extrahepatic disease during the followup period, since patients with only 1 liver metastasis presented extrahepatic disease significantly less often compared to the rest of the population ( $15.58 \%$ vs. $84.42 \%, \mathrm{P}=0.02)$.

Overall survival at 1,3 and 5 years was $96.8 \%, 68.7 \%$ and $34.3 \%$, respectively. Fourteen patients died of cancer, while 7
Table 1 Patients' demographics and clinicopathological characteristics

\begin{tabular}{lcc} 
Characteristics & \multicolumn{2}{c}{ Value } \\
\hline Age $(\text { years })^{1}$ & $51-88(70.96,72.5,9.94)$ \\
Tumor diameter $(\mathrm{cm})^{1}$ & $0.8-3.9(1.85,1.85,0.67)$ \\
\hline & Frequency & Percentage \\
\hline & & \\
\hline Sex & 21 & 65.6 \\
$\quad$ Male & 11 & 34.4 \\
Female & & \\
Primary tumor & 27 & 84.4 \\
Colon & 5 & 15.6 \\
Rectum & & \\
Number of hepatic metastases & 16 & 50 \\
1 & 11 & 34.4 \\
2 & 4 & 12.5 \\
3 & 1 & 3.1 \\
4 & & \\
Diameter of metastases & \\
$\leq 2 \mathrm{~cm}$ & 15 & 46.9 \\
$>2 \mathrm{~cm}$ & 17 & 53.1 \\
\hline
\end{tabular}

${ }^{1}$ Data in parenthesis are expressed as mean, median, standard deviation ${ }^{2}$ Number of patients who had at least 1 tumor greater or smaller than $2 \mathrm{~cm}$

died of other reasons, including myocardial infarction, stroke and pulmonary embolism. Those 7 patients were excluded from the survival analysis. Of the patients still alive at their last follow-up visit, $54 \%(6 / 11)$ were disease-free.

Disease-free survival ranged between 3 and 60 months (mean 30, median: 15 months). In the univariate analysis, patients who had at least one liver metastasis greater than 2 $\mathrm{cm}$ in diameter $(\mathrm{n}=17)$ had worse 5 -year disease-free survival compared to the rest of the group (20.06 vs. $40.64, \mathrm{P}=0.04$ ) (Table 2, Fig. 3); this finding was further confirmed in the multivariate analysis (Table 3 ).

Overall survival ranged between 11 and 60 months (mean: 42.64, median: 48 months). In the univariate analysis, a statistically significant difference in 5-year overall survival was recorded between patients who had 1 liver metastasis $(n=13)$ and those who had more $(\mathrm{n}=12)(55.00$ vs. $29.25, \mathrm{P}=0.01)$ at initial presentation (Table 2, Fig. 4). This was also confirmed in the multivariate analysis (Table 3 ).

None of the remaining clinicopathological factors examined, including patients' age, sex and incomplete MWA, repeated 1 month later, was found to be associated with the clinical outcome defined by the overall and disease-free survival (Table 2).

Seven patients mentioned pain in the right hypochondrium, referring to the ipsilateral shoulder in a few of them. All these patients were treated with systemic oral analgesics and reported pain resolution less than 1 week after the procedure.

\section{Discussion}

Hepatic metastases occur in approximately $50 \%$ of patients with colorectal cancer [6-8]. Although surgical resection has 

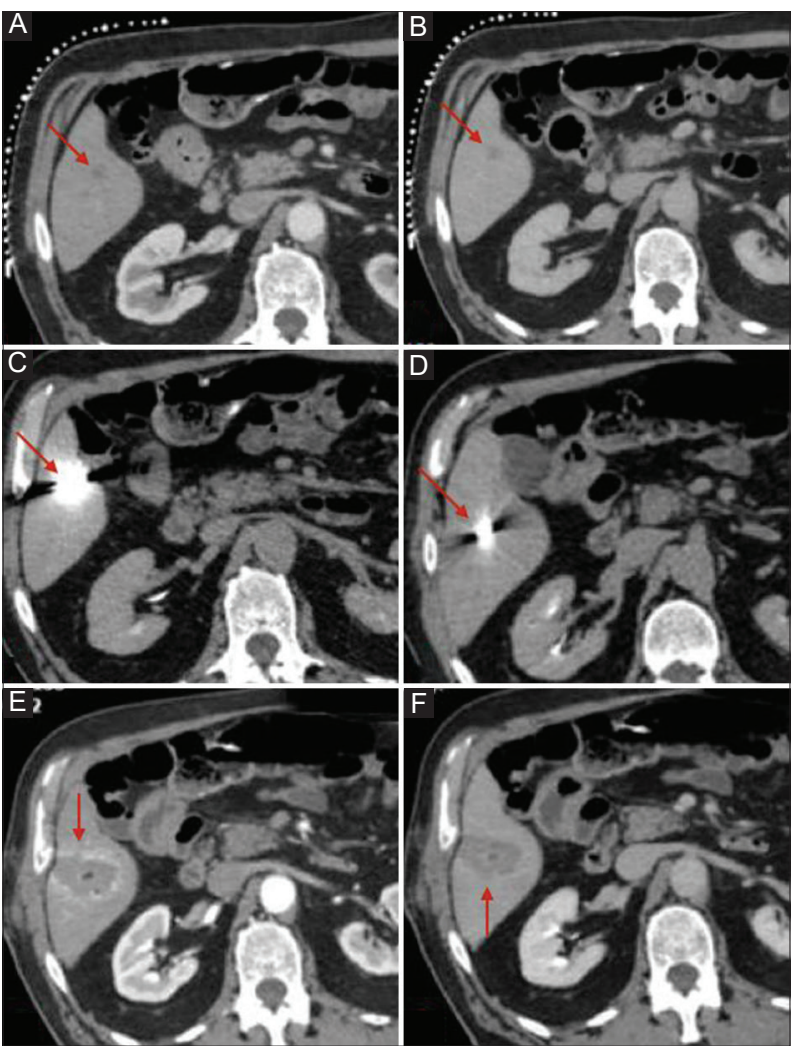

Figure 1 Patient with colorectal cancer and metachronous hepatic metastases, $1.2 \mathrm{~cm}$ in diameter, treated with microwave ablation (MWA) under computed tomography (CT) guidance. (A) Liver CT scan in arterial phase: hypodense lesion in segment VI (red arrow). (B) Liver CT scan in portal venous phase: hypodense lesion with rim-like enhancement in segment VI (red arrow). (C, D) Liver CT scan during the procedure depicts the final position of the MWA antenna (red arrow). (E, F) Contrast-enhanced liver CT scan at the end of the procedure in the arterial (E) and venous (F) phase depicts the ablation zone as a non-enhancing area of low attenuation with a uniform peripheral rim of enhancement, representing benign reactive inflammation to thermal injury (red arrow)

historically been the mainstay of treatment, with the highest success rates and a 5-year survival rate ranging from 24$58 \%$, more than $70 \%$ of patients are non-surgical candidates despite the recent advances and developments in surgical techniques [6-8]. Therefore, minimally invasive techniques of thermal ablation constitute an alternative method for the treatment of non-resectable hepatic metastases and are increasingly used to prolong the survival of patients with chemotherapy alone or without any intervention [9-12]. Clinical outcomes are promising, with 5-year survival rates of 24-44\%, similar to those for surgical resection [13-15].

Percutaneous MWA is a relatively new method of thermal ablation that is growing in popularity because of its potential advantages over RFA. There are data in the literature that support the efficacy and safety of MWA for the treatment of liver metastases, but there are only few studies with long-term results [4].

Our study presents the results of a 5-year follow up of 32 patients with colorectal cancer metastases who underwent

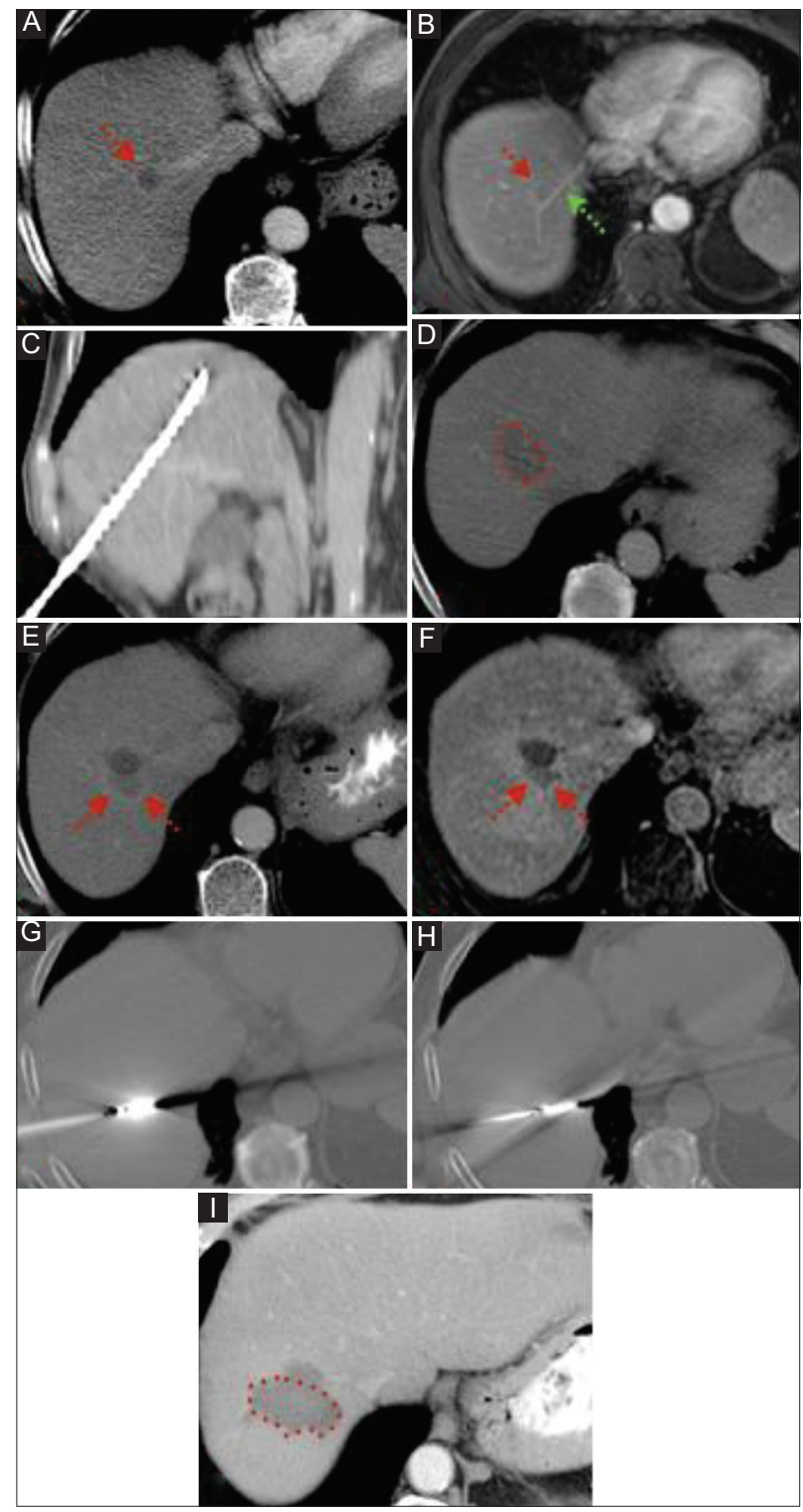

Figure 2 Patient with history of rectal cancer and metachronous solitary hepatic lesion of $1.5 \mathrm{~cm}$ in diameter in segment VII. (A, B) Contrastenhanced computed tomography (CT) and magnetic resonance imaging (MRI) scan: hepatic lesion with rim-like enhancement (red arrow) in close proximity to the right hepatic vein (green arrow). (C) CT scancoronal reconstruction depicts the final position of the MWA antenna. (D) Contrast-enhanced CT scan at the end of the procedure: hypodense area of necrosis without evidence of viable tumor. (E, F) Contrastenhanced CT and MRI scan at 12-month follow up: low attenuation area with peripheral enhancement in close proximity to the ablation zone, compatible with local recurrence $(\mathrm{G}, \mathrm{H}) \mathrm{CT}$ scan depicts the final position of the microwave antenna ( 2 overlapping ablations were performed). (I) Contrast-enhanced CT scan at 3-month follow up: low attenuation area without enhancement compatible with complete necrosis

percutaneous MWA. The 3- and 5-year survival rates of our study population were $68.7 \%$ and $34.3 \%$, respectively, and are similar to those reported in other studies with MWA [16-19]. Yoshiyuki Wada reported 3- and 5-year survival outcomes of $44.6 \%$ and $33.7 \%$, respectively, in patients with at least 5 
Table 2 Five-year overall and disease-free survival according to clinicopathological variables in 32 patients with liver metastases treated with microwave ablation

\begin{tabular}{lcccc}
\hline Variable (n) & $\begin{array}{c}\text { 5-year } \\
\text { survival }\end{array}$ & P-value & $\begin{array}{c}\text { 5-year } \\
\text { DFS }\end{array}$ & P-value \\
& 43.18 & 0.88 & 28.09 & 0.99 \\
\hline Age & 42.21 & & 31.17 & \\
$\quad$ >70 years (11) & & & & \\
$\quad>70$ years (14) & 42.11 & 0.73 & 31.95 & 0.59 \\
Sex & 43.70 & & 25.66 & \\
$\quad$ Male (17) & & & & \\
$\quad$ Female (8) & 46.23 & 0.12 & 40.64 & 0.04 \\
$\quad$ Tumor diameter & 38.25 & & 20.06 & \\
$\quad<2$ cm (15) & & & & \\
$\quad \geq 2$ cm (17) & 55.00 & 0.01 & 36.14 & 0.09 \\
$\quad$ Number of tumors & 29.25 & & 24.16 & \\
$\quad=1$ (13) & & & & \\
$\quad>1$ (12) & 50.33 & 0.94 & 29.00 & 0.85 \\
$\quad$ Repeat MWA (at 1 ${ }^{\text {st }}$ month) & 41.59 & & 30.11 & \\
$\quad$ Yes (3) & & & & \\
$\quad$ No (22) & & & & \\
\hline
\end{tabular}

DFS, disease-free survival; $M W A$, microwave ablation

Table 3 Multivariate analysis in patients who underwent MWA

\begin{tabular}{|c|c|c|c|c|}
\hline \multirow[t]{2}{*}{ Variable } & \multicolumn{2}{|c|}{5 -year survival } & \multicolumn{2}{|c|}{$\begin{array}{c}\text { 5-year disease-free } \\
\text { survival }\end{array}$} \\
\hline & $\begin{array}{l}\text { Hazard ratio } \\
(95 \% \mathrm{CI})\end{array}$ & P-value & $\begin{array}{l}\text { Hazard ratio } \\
(95 \% \mathrm{CI})\end{array}$ & P-value \\
\hline Age $^{*}$ & $\begin{array}{c}0.43 \\
(0.12-1.55)\end{array}$ & 0.19 & $\begin{array}{c}0.50 \\
(0.16-1.59)\end{array}$ & 0.24 \\
\hline Sex & $\begin{array}{c}0.53 \\
(0.13-2.13)\end{array}$ & 0.37 & $\begin{array}{c}0.88 \\
(0.30-2.55)\end{array}$ & 0.81 \\
\hline Tumor size ${ }^{* *}$ & $\begin{array}{c}4.1 \\
(1.66-20.44)\end{array}$ & 0.08 & $\begin{array}{c}3.03 \\
(1.05-10.31)\end{array}$ & 0.04 \\
\hline $\begin{array}{l}\text { Number of } \\
\text { tumors }^{1}\end{array}$ & $\begin{array}{c}24.02 \\
(3.71-155.44)\end{array}$ & 0.001 & $\begin{array}{c}2.71 \\
(0.87-8.45)\end{array}$ & 0.08 \\
\hline Repeated MWA & $\begin{array}{c}1.86 \\
(0.24-14.49)\end{array}$ & 0.55 & $\begin{array}{c}0.91 \\
(0.16-5.26)\end{array}$ & 0.92 \\
\hline \multicolumn{5}{|c|}{ MWA, microwave ablation; $C I$, confidence interval } \\
\hline $\begin{array}{l}{ }^{*} \text { cut value } 2 \mathrm{~cm} \\
{ }^{1} \text { cut value } 1 \text { tumor }\end{array}$ & & & & \\
\hline
\end{tabular}

or more colorectal cancer metastases who underwent only MWA and chemotherapy, whereas the disease was considered non-resectable [16]. Similarly, Eng et al reported a 4-year overall survival of $35.2 \%$ in 33 patients who had metastatic colorectal cancer with a maximum lesion diameter of 5.5 $\mathrm{cm}$, treated with intraoperative MWA [17]. Wang et al found a $78.65 \%$ 3-year survival rate in 115 patients with colorectal liver metastases treated with percutaneous MWA under ultrasound guidance [19]. Similar long-term survival rates have been reported in studies following RFA for the treatment of hepatic metastases from colorectal cancer [13,20,21]. Solbiati et al reported 3- and 5-year survival rates of $69 \%$ and

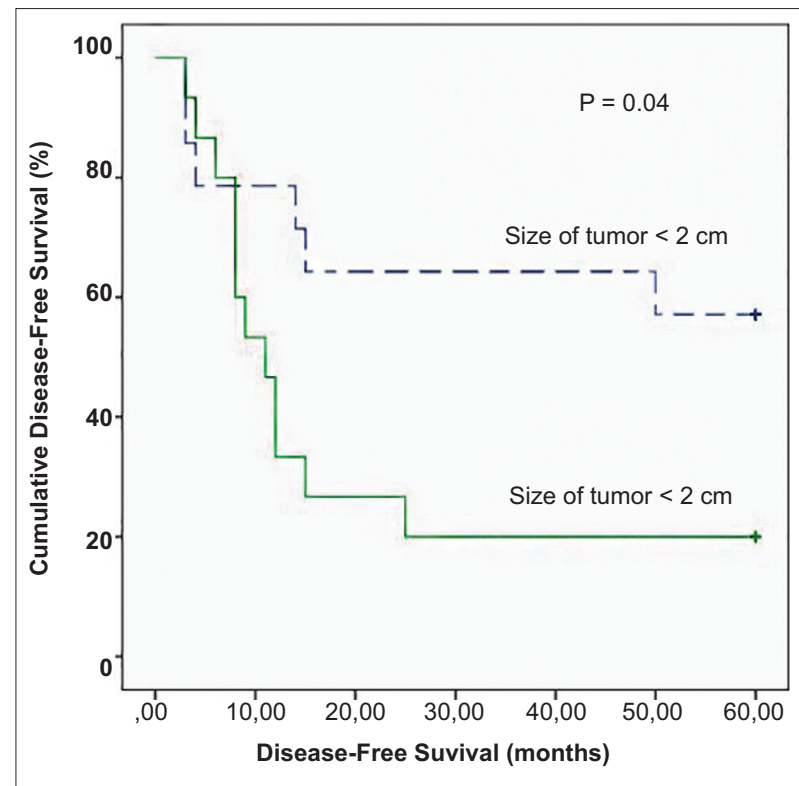

Figure 3 Kaplan-Meier survival curve demonstrating significantly worse 5-year disease-free survival in patients who had at least 1 liver tumor greater than $2 \mathrm{~cm}$ in diameter at presentation

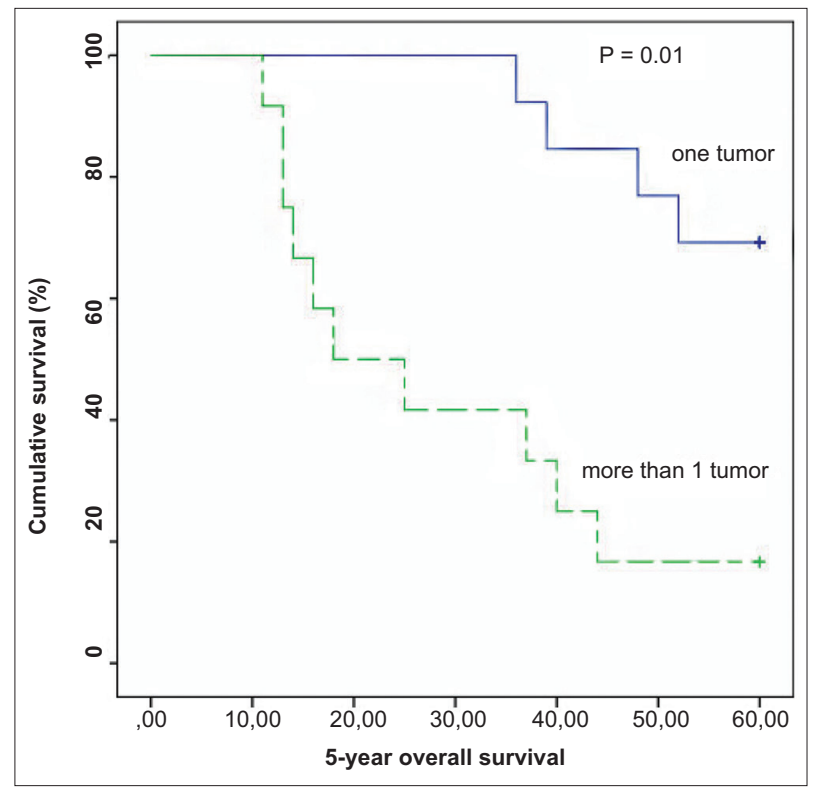

Figure 4 Kaplan-Meier survival curve demonstrating significantly worse 5 -year overall survival in patients who had 2 or more liver metastases at presentation

$48 \%$, respectively, similar to those in our study, in 99 patients with colorectal cancer metastases treated with RFA [14]. These rates are comparable to the 5-year survival rates after surgical resection (24-58\%) [22-25]. Recently, the results of a metaanalysis were published comparing MWA with RFA for the treatment of hepatocellular carcinoma and liver metastases. The authors concluded that MWA is at least as safe and effective as RFA for treating liver cancer and demonstrated significantly lower rates of local tumor progression [26]. 
Univariate and multivariate analysis showed that only the number of liver metastases, at the initial presentation, significantly affected patients' overall survival. The 5-year overall survival rate was $55 \%$ for patients with a solitary hepatic metastasis, vs. $29.5 \%$ for patients with 2 or more hepatic metastases. In addition, the total number of liver metastases at presentation appeared to be a prognostic factor for extrahepatic disease during the follow up, as patients with solitary hepatic metastases developed extrahepatic metastases at a much lower rate $(15.58 \%)$ than the rest of the study population $(84.42 \%)$.

Several studies that evaluated data following surgical resection of hepatic metastases have concluded that the number of metastases (usually more than 3) was an independent predictor factor of tumor recurrence, with poorer long-term results according to multivariate analysis $[27,28]$. A study by Siperstein et al [29] showed a significant difference in overall median survival (27 vs. 17 months) in 234 patients, based on the presence of fewer or more than 3 metastases at initial presentation. Likewise, studies of thermal ablation with RF have shown better long-term outcomes in patients with smaller and fewer tumors.

The univariate and multivariate analysis of our data also revealed that patients with at least one liver metastasis $>2$ $\mathrm{cm}$ in maximum diameter had worse 5-year disease-free survival compared to patients with liver metastases $<2 \mathrm{~cm}$ in maximum diameter ( $20 \%$ vs. $40 \%$ ); however, the difference in these patients' overall survival was not statistically significant. The size of a tumor for ablation is a well-known predictor of local tumor recurrence, and many researchers claim it to be the major factor. Therefore, it can affect the disease-free survival. Mulier [30] published the results of a multivariate analysis of the factors affecting local recurrence after percutaneous and intraoperative RFA in 5224 hepatic tumors and showed that the rate of local recurrence was $16 \%$ and $3.6 \%$, respectively, for tumors $<3 \mathrm{~cm}$ in diameter, and $25.9 \%$ and $21.7 \%$, respectively, for tumors from $3 \mathrm{~cm}$ to $5 \mathrm{~cm}$ in diameter. Likewise, in our study, the local recurrence rate was much higher for metastases $>3 \mathrm{~cm}$ versus metastases $<3 \mathrm{~cm}$, as local recurrence was observed in $13 \%$ of metastases with a diameter $<3 \mathrm{~cm}$ and in $50 \%$ of metastases with a diameter $>3.1 \mathrm{~cm}$. However, the literature does not support the size of liver metastases at baseline as a prognostic factor for new metastases.

In conclusion, we reported the long-term follow-up results, up to 5 years, of 32 patients with 58 liver metastases from colorectal cancer treated with percutaneous MWA. Our results are comparable to those of previous series of patients treated with percutaneous thermal ablation, and substantially similar to the results after surgical resection. These findings highlight the safety and efficacy of percutaneous MWA for the treatment of liver metastases from colorectal cancer and emphasize the usefulness of thermal ablation as an alternative treatment for the large number of patients who are not surgical candidates or refuse surgical resection and selectively in specific subgroups of patients with resectable disease.

\section{Summary Box}

\section{What is already known:}

- Hepatic metastases occur in approximately $50 \%$ of patients with colorectal cancer

- For colorectal cancer metastatic liver disease, apart from systemic chemotherapy, additional therapeutic options include surgery and interventional oncology techniques, such as percutaneous thermal destruction of metastatic lesions or loco-regional control of metastatic liver disease with intra-arterial therapies

- The efficacy, safety and long-term outcomes of percutaneous radiofrequency ablation for the treatment of colorectal liver metastases has been well demonstrated in the literature

\section{What the new findings are:}

- Computed tomography-guided percutaneous microwave ablation for metastatic liver-only disease in patients with colorectal cancer and oligometastatic disease is a feasible, safe and effective therapy with satisfactory long-term survival rates

- The number of liver metastases at initial presentation significantly affected patients' overall survival

- The size of a tumor for ablation has been shown to be a predictor of local tumor recurrence and can affect disease-free survival

\section{References}

1. Torre LA, Bray F, Siegel RL, Ferlay J, Lortet-Tieulent J, Jemal A. Global cancer statistics, 2012. CA Cancer J Clin 2015;65:87-108.

2. Ferlay J, Soerjomataram I, Dikshit R, et al. Cancer incidence and mortality worldwide: sources, methods and major patterns in GLOBOCAN 2012. Int J Cancer 2015; 136:E359-E386.

3. Van Cutsem E, Cervantes A, Adam R, et al. ESMO consensus guidelines for the management of patients with metastatic colorectal cancer. Ann Oncol 2016;27:1386-1422.

4. Lubner MG, Brace CL, Hinshaw JL, Lee FT Jr. Microwave tumour ablation: mechanism of action, clinical results, and devices. $J$ Vasc Interv Radiol 2010;21 (8 Suppl):S192-S203.

5. Filippiadis DK, Binkert C, Pellerin O, Hoffmann RT, Krajina A, Pereira PL. Cirse quality assurance document and standards for classification of complications: the cirse classification system. Cardiovasc Interv Radiol 2017;40:1141-1146.

6. Van Cutsem E, Nordlinger B, Adam R, et al; European Colorectal Metastases Treatment Group. Towards a pan-European consensus on the treatment of patients with colorectal liver metastases. Eur J Cancer 2006;42:2212-2221.

7. Zorzi D, Mullen JT, Abdalla EK, et al. Comparison between hepatic wedge resection and anatomic resection for colorectal liver metastases. J Gastrointest Surg 2006;10:86-94. 
8. Covey AM, Brown KT, Jarnagin WR, et al. Combined portal vein embolization and neoadjuvant chemotherapy as a treatment strategy for resectable hepatic colorectal metastases. Ann Surg 2008;247:451-455.

9. Ruers T, Punt C, Van Coevorden F, et al; EORTC Gastro-Intestinal Tract Cancer Group, Arbeitsgruppe Lebermetastasen undtumoren in der Chirurgischen Arbeitsgemeinschaft Onkologie (ALM-CAO) and the National Cancer Research Institute Colorectal Clinical Study Group (NCRI CCSG). Radiofrequency ablation combined with systemic treatment versus systemic treatment alone in patients with non-resectable colorectal liver metastases: a randomized EORTC Intergroup phase II study (EORTC 40004). Ann Oncol 2012;23:2619-2626.

10. Tanis E, Nordlinger B, Mauer, M, et al. Local recurrence rates after radiofrequency ablation or resection of colorectal liver metastases. Analysis of the European Organisation for Research and Treatment of Cancer \#40004 and \#40983. Eur J Cancer 2014;50:912-919.

11. Nishiwada S, Ko S, Mukogawa T, et al. Comparison between percutaneous radiofrequency ablation and surgical hepatectomy focusing on local disease control rate for colorectal liver metastases. Hepatogastroenterology 2014;61:436-441.

12. Berber E, Tsinberg $\mathrm{M}$, Tellioglu G, Simpfendorfer $\mathrm{CH}$, Siperstein AE. Resection compared to laparoscopic radiofrequency thermal ablation of solitary colorectal liver metastasis. J Gastrointest Surg 2008;12:1967-1972.

13. Gillams AR, Lees WR. Five-year survival in 309 patients with colorectal liver metastases treated with radiofrequency ablation. Eur Radiol 2009;19:1206-1213.

14. Solbiati L, Ahmed M, Cova L, Ierace T, Brioschi M, Goldberg SN. Small liver colorectal metastases treated with percutaneous radiofrequency ablation: local response rate and long-term survival with up to 10-year follow-up. Radiology 2012;265:958-968.

15. Veltri A, Sacchetto P, Tosetti I, Pagano E, Fava C, Gandini G. Radiofrequency ablation of colorectal liver metastases: small size favorably predicts technique effectiveness and survival. Cardiovasc Intervent Radiol 2008;31:948-956.

16. Wada Y, Takami Y, Tateishi M, Ryu T, Mikagi K, Saitsu H. Efficacy of surgical treatment using microwave coagulo-necrotic therapy for unresectable multiple colorectal liver metastases. Onco Targets Ther 2016;9:937-943.

17. Eng OS, Tsang AT, Moore D, et al. Outcomes of microwave ablation for colorectal cancer liver metastases: a single center experience. $J$ Surg Oncol 2015;111:410-413.

18. Groeschl RT, Pilgrim CH, Hanna EM, et al. Microwave ablation for hepatic malignancies: a multiinstitutional analysis. Ann Surg
2014;259:1195-1200.

19. Wang J, Liang P, Yu J, et al. Clinical outcome of ultrasound-guided percutaneous microwave ablation on colorectal liver metastases. Oncol Lett 2014;8:323-326.

20. Hammill CW, Billingsley KG, Cassera MA, Wolf RF, Ujiki MB, Hansen PD. Outcome after laparoscopic radiofrequency ablation of technically resectable colorectal liver metastases. Ann Surg Oncol 2011;18:1947-1954.

21. Van Tilborg AA, Meijerink MR, Sietses C, et al. Long-term results of radiofrequency ablation for unresectable colorectal liver metastases: a potentially curative intervention. $\mathrm{Br} J$ Radiol 2011;84:556-565.

22. Karanicolas PJ, Jarnagin WR, Gonen M, et al. Long-term outcomes following tumour ablation for treatment of bilateral colorectal liver metastases. JAMA Surg 2013;148:597-601.

23. Abdalla EK, Vauthey JN, Ellis LM, et al. Recurrence and outcomes following hepatic resection, radiofrequency ablation, and combined resection/ablation for colorectal liver metastases. Ann Surg 2004;239:818-825.

24. Choti MA, Sitzmann JV, Tiburi MF, et al. Trends in long-term survival following liver resection for hepatic colorectal metastases. Ann Surg 2002;235:759-766.

25. Fernandez FG, Drebin JA, Linehan DC, Dehdashti F, Siegel BA, Strasberg SM. Five-year survival after resection of hepatic metastases from colorectal cancer in patients screened by positron emission tomography with F-18 fluorodeoxyglucose (FDG-PET). Ann Surg 2004;240:438-447.

26. Glassberg MB, Ghosh S, Clymer JW, et al. Microwave ablation compared with radiofrequency ablation for treatment of hepatocellular carcinoma and liver metastases: a systematic review and meta-analysis. Onco Targets Ther 2019;12:6407-6438.

27. Adam R, Frilling A, Elias D, et al; Liver MetSurvey Centres. Liver resection of colorectal metastases in elderly patients. Br J Surg 2010;97:366-376.

28. Fuks D, Cook MC, Bréhant O, et al. Colorectal carcinoma with potentially resectable metastases: factors associated with the failure of curative schedule. Gastroenterol Clin Biol 2008;32:390-400.

29. Siperstein AE, Berber E, Ballem N, Parikh RT. Survival after radiofrequency ablation of colorectal liver metastases: 10-year experience. Ann Surg 2007;246:559-565.

30. Mulier S, Ni Y, Jamart J, Ruers T, Marchal G, Michel L. Local recurrence after hepatic radiofrequency coagulation: multivariate meta-analysis and review of contributing factors. Ann Surg 2005;242:158-171. 